\title{
BRINQUEDO TERAPÊUTICO NO PREPARO DA CRIANÇA PARA PUNÇÃO VENOSA AMBULATORIAL: PERCEPÇÃO DOS PAIS E ACOMPANHANTES
}

\author{
Therapeutic play when preparing the child for venipuncture outpatient: perception from \\ the parents and attendants. \\ El juego terapéutico en la preparación del niño para una punción venosa en ambulatorio: \\ percepción de los padres y acompañantes.
}

Caroline Monteiro Conceição ${ }^{1}$
Conceição Vieira da Silva Ohara $^{4}$

Circéa Amalia Ribeiro²

Paula Rosenberg de Andrade 5

\section{RESUMO}

Estudo descritivo qualitativo com o objetivo de compreender a percepção de pais e acompanhantes sobre o emprego do Brinquedo Terapêutico no preparo da criança para a punção venosa ambulatorial, realizado em um ambulatório da cidade de São Paulo. Os dados foram coletados por meio de entrevistas semiestruturadas realizadas com oito pais ou acompanhantes de crianças preparadas para a punção venosa com o Brinquedo Terapêutico e, após, submetidos à análise qualitativa de conteúdo. Os resultados evidenciaram que eles aprovam essa estratégia de preparo e acreditam que esta favorece o conhecimento sobre 0 procedimento, diminui o medo, acalma e promove a segurança deles e da criança, além de constituir-se em um atendimento de enfermagem humanizado e de qualidade à criança e família. Reitera-se a importância da implementação do Brinquedo Terapêutico na assistência à criança em ambulatórios e unidades básicas de saúde.

Palavras-chave: Jogos e Brinquedos. Procedimentos Clínicos. Assistência Ambulatorial. Enfermagem Pediátrica.

\begin{abstract}
This qualitative descriptive study aimed to understand the perception from the parents and attendants about the use of Therapeutic Play when preparing their children for venipuncture, followed by blood collection. This study was performed in an outpatient clinic in the city of Sao Paulo. Data were collected using semi-structured interviews, conducted with eight parents of children who had been prepared with the play for the blood collection. These data were subsequently submitted to qualitative content analysis. Results showed that parents approved this preparation strategy and considered it to promote knowledge about the procedure, reduce the fear, have a soothing effect, and increase parents' and child's sense of security, in addition to this, it contributes to a humanized nursing care for the child and family. Finally, the importance of implementing the Therapeutic Play in child care provided in outpatient clinics and basic health units should be emphasized.
\end{abstract}

Keywords: Play and playthings. Critical pathways. Ambulatory care. Pediatric nursing.

\section{Resumen}

Estudio descriptivo cualitativo realizado con el objetivo de comprender la percepción de los padres y acompañante a respecto de la utilización del Juego Terapéutico en la preparación de sus hijos para la punción venosa previa a la recolección de sangre. Fue realizado en un ambulatorio de la ciudad de São Paulo. Los datos fueron recolectados por medio de entrevistas seme-estructuradas realizadas con ocho padres o acompañantes de niños preparados con el juego para la recolección de sangre, y que, después, fueron sometidos al análisis cualitativo del contenido. Los resultados evidenciaron que los padres aprueban esa estrategia de preparación y consideran que la misma favorece al conocimiento sobre el procedimiento, disminuye el miedo, tranquiliza y promueve la seguridad de los adultos y de los niños, además de ser una atención de enfermería humanizada y de calidad al niño y a la familia. Se reitera la importancia de la implementación del Juego Terapéutico en la asistencia al niño en ambulatorios y en unidades básicas de salud.

Palabras clave: Juego e implementos del juego. Procedimientos clínicos. Atención en ambulatorio. Enfermería pediátrica.

\footnotetext{
'Enfermeira da UTI Neonatal do Hospital São Paulo e da UTI Pediátrica do Hospital Infantil Darcy Vargas. Ex-graduanda de Enfermagem da Escola Paulista de Enfermagem da Universidade Federal de São Paulo. São Paulo-SP. Brasil. E-mail: carolcarolmc@yahoo.com.br, ${ }^{2}$ Doutora em Enfermagem, Professor Associado do Departamento de Enfermagem da Escola Paulista de Enfermagem da Universidade Federal de São Paulo. São Paulo-sp. Brasil. E-mail: caribeiro@unifesp.br, ${ }^{3}$ Doutora em Enfermagem, Professor Adjunto do Departamento de Enfermagem da Escola Paulista de Enfermagem da Universidade Federal de São Paulo. São Paulo-SP. Brasil. E-mail: rihborba@nunifesp.br, ${ }^{4}$ Doutora em Enfermagem, Professor Associado do Departamento de Enfermagem da Escola Paulista de Enfermagem da Universidade Federal de São Paulo. São Paulo-SP. Brasil. E-mail: c.silva27@unifesp.br, ${ }^{5}$ Mestre em Ciências, Doutoranda do Programa de Pós-Graduação em Enfermagem da Escola Paulista de Enfermagem da Universidade Federal de São Paulo, Brasil. Enfermeira do Centro Assistencial Cruz de Malta. São Paulo - SP. Brasil. E-mail: paularandrade@uol.com.br
} 


\section{INTRODUÇÃO}

A vivência de procedimentos intrusivos que envolvem o emprego de agulhas, como a punção venosa, particularmente, é estressante tanto à criança como a seus pais ou acompanhantes. Esses procedimentos chegam a ser aterrorizantes, desencadeiam sentimentos de raiva e determinam que as crianças mantenham-se em constante estado de alerta, tentando reconhecer a iminência de sua aproximação. ${ }^{1}$

A injeção é considerada um dos eventos mais ameaçadores à criança porque é percebida como uma invasão extremamente dolorosa em seu corpo, um ato hostil e mutilador. ${ }^{2}$ As crianças referem que se sentem machucadas pelas agulhas e que estas desencadeiam o medo da dor e do procedimento em si.

Com relação aos fatores do estresse vivido pelos pais, destaca-se o sofrimento com o ritual dos procedimentos. A mãe sofre assistindo o sofrimento do filho, sofre com o filho pelo fato de vê-lo sofrendo, especialmente nas situações em que ele é submetido a procedimentos terapêuticos dolorosos à sua frente, sem que possa fazer algo para evitar ou minimizar sua dor. ${ }^{3}$

Especificamente no que se refere à punção venosa, 0 comportamento do filho faz com que a mãe conclua ser uma experiência dolorosa para ele; que aquele momento ficou na lembrança do filho como algo ruim, porque talvez para ela também tenha sido uma experiência que traz lembranças de dor e sofrimento. ${ }^{4}$ Embora reconheça sua necessidade e importância na terapêutica da criança, ela sente dó, sente-se mal e culpada, sendo que certas mães participam do procedimento e outras preferem não presenciá-lo. ${ }^{5}$

Na tentativa de minimizar o sofrimento da criança, um dos recursos que têm sido preconizados na assistência de enfermagem é o Brinquedo Terapêutico (BT), reconhecido como importante instrumento de intervenção no preparo para procedimentos, favorecendo sua compreensão, minimizando 0 estresse decorrente dessa vivência e promovendo seu bemestar psicofisiológico. Para tanto, o BT é usado em sua modalidade Instrucional (BTI), que objetiva explicar o procedimento à criança por meio de sua demonstração e/ou dramatização, possibilitando-lhe visualizar e manusear os materiais que serão utilizados ou brinquedos que os representem. ${ }^{6}$

Um estudo que buscou verificar a aplicabilidade de um protocolo para o preparo da criança pré-escolar hospitalizada que seria submetida à punção venosa, com o uso do BT, identificou que esta intervenção mostrou-se positiva, visto que as crianças tornaram-se mais cooperativas; demonstraram ter compreendido a necessidade e a técnica do procedimento; tiveram oportunidade de exteriorizar seus sentimentos de mágoa e revolta contra o mesmo e contra os profissionais que os realizaram; puderam elaborar situações familiares traumáticas e passaram a se relacionar melhor com as outras crianças e a equipe de enfermagem. ${ }^{7}$
Outro estudo a respeito do efeito de BT sobre o comportamento de crianças de 3 a 6 anos, durante a coleta de sangue para exames laboratoriais, verificou que o BT mostrouse um instrumento eficaz para o preparo deste procedimento, pois favoreceu a compreensão e o controle das reações da criança, decorrentes dessa situação. ${ }^{8}$

É importante ressaltar que a utilização do BT atende ao preconizado pela resolução 295/2004 do Conselho Federal de Enfermagem que estabelece a competência do enfermeiro para uso dessa intervenção na assistência à criança e família ${ }^{6}$, assim como cumpre as determinações do Estatuto da Criança e do Adolescente - ECA que, em seu Artigo. 16, garante-lhes o direito à liberdade, compreendendo o brincar, praticar esportes e divertir-se. ${ }^{9}$

Também está de acordo com seu Artigo 18, segundo o qual "É dever de todos velar pela dignidade da criança e do adolescente, pondo-os a salvo de qualquer tratamento desumano, violento, aterrorizante, vexatório ou constrangedor" ${ }^{\prime \prime}$, pois, com a utilização do BT, os profissionais de enfermagem atuam de forma humanizada, respeitando 0 meio de comunicação mais eficaz da criança, o brincar.

A utilização do brincar na assistência à criança tem sido objeto de várias pesquisas em nosso país, com ênfase especial no contexto hospitalar. ${ }^{10}$ Este estudo foi realizado em uma unidade ambulatorial na qual o BTI tem sido utilizado sistematicamente como instrumento de preparo da criança que vai ser submetida à punção venosa para exames laboratoriais. Pais e acompanhantes de crianças atendidas nesta instituição, que foram preparadas para tal procedimento com o BTI, informalmente, têm referido o efeito benéfico deste preparo sobre o comportamento de seus filhos.

Aprofundar a compreensão dessa vivência é importante para avaliarmos essa ação assistencial, pois, a partir do ponto de vista da própria população atendida, é construído o conhecimento sobre a temática. Assim, o estudo teve como objetivo: compreender a percepção de pais e acompanhantes sobre o emprego do Brinquedo Terapêutico no preparo da criança para a punção venosa ambulatorial.

\section{MÉTODO}

Trata-se de um estudo descritivo, de natureza qualitativa, abordagem que se preocupa com a realidade que não pode ser quantificada, porque se aprofunda no mundo dos significados, motivos, crenças, valores e atitudes que correspondem a um espaço mais profundo das relações. ${ }^{11}$

0 estudo ocorreu no ambulatório do Centro Assistencial Cruz de Malta (CACM), instituição filantrópica conveniada ao Sistema Único de Saúde e à Prefeitura Municipal de São Paulo, que oferece à comunidade serviços de creche, centro de juventude e assistência ambulatorial prioritariamente materna e infantil. Grande parte da população assistida pertence a uma classe socioeconômica pouco favorecida e reside em bolsões de pobreza. 
Os sujeitos da pesquisa foram oito acompanhantes de crianças submetidas à punção venosa no ambulatório do CACM, que tinham entre dois e sete anos de idade e haviam sido preparadas com o BTI para esse procedimento: cinco mães, um pai, uma avó e uma cuidadora responsável pela criança. Por ser um trabalho qualitativo, o número de sujeitos foi determinado pelo processo de saturação, cessando quando os dados coletados tornaram-se repetitivos, permitindo a compreensão da vivência estudada. ${ }^{1}$

No ambulatório em questão, o agendamento das crianças para coleta de sangue para exames laboratoriais é realizado em dia espeć́fico da semana, separado da coleta dos adultos, e o preparo com o BTI é feito pela enfermeira da instituição. Durante o período letivo, o preparo é realizado pelos alunos do segundo ano de graduação de uma universidade pública federal da cidade de São Paulo, acompanhados por um professor.

As crianças são chamadas em grupos de cinco ou seis e encaminhadas, juntamente com os pais ou responsáveis, a uma antessala contígua àquela onde a coleta de sangue é realizada, e lhes é contada a história de uma criança que será submetida à punção venosa por precisar fazer exame de sangue, e esse procedimento é, concomitantemente, demonstrado em uma boneca. Depois disso, as crianças são convidadas a repetir a dramatização em bonecos de pano, com os objetos reais utilizados nas punções: seringas, agulhas, garrotes, tubos de ensaio e outros, sendo acompanhadas e supervisionadas pelos alunos, ou pela enfermeira.

Os dados foram coletados de novembro de 2007 a março de 2008 por meio de entrevistas individuais semiestruturadas, realizadas em uma sala da instituição, especialmente reservada para esse fim, após as crianças já terem sido preparadas com o BTI e submetidas à punção venosa. As entrevistas foram iniciadas com a seguinte pergunta orientadora: o que o senhor (a) achou do preparo de seu filho para a punção venosa com o Brinquedo Terapêutico? No transcorrer da entrevista, outras perguntas foram formuladas, no sentido de aprofundar a compreensão dessa vivência para os pais. As entrevistas foram gravadas e transcritas na íntegra, para serem analisadas.

Conforme preconizado pela resolução 196/96 do Conselho Nacional de Saúde, a coleta de dados iniciou-se, após aprovação do projeto pelo Comitê de Ética em Pesquisa da Universidade Federal de São Paulo, sob o número 1.072/04, e os sujeitos participantes assinaram o Termo de Consentimento Livre e Esclarecido.

Os dados foram submetidos à análise qualitativa de conteúdo, seguindo as etapas de codificação e categorização na busca de construção de categorias temáticas representativas do fenômeno estudado. A codificação é o processo de identificação de palavras, frases e temas persistentes dentro dos dados, que exprimam conceitos significativos para atender aos objetivos propostos. A categorização consiste na releitura dos códigos, classificando-os e agrupando-os por similaridade, segundo suas características conceituais, determinando as categorias. $^{12}$

\section{RESULTADOS}

A análise dos dados permitiu a compreensão da percepção dos pais e acompanhantes quanto à utilização do BT no preparo da criança para a punção venosa, revelando as seguintes categorias temáticas: A punção venosa sendo fonte de sofrimento para os pais e acompanhantes; Aprovando o preparo da criança com o BT; Surpreendendo-se com a proposta e os resultados do preparo; Reconhecendo os avanços e o valor da equipe de enfermagem.

A seguir, estas são descritas e ilustradas, com exemplos extraídos dos discursos dos pais, que estão identificados com nomes fictícios de personagens do cenário artístico e literário: Cora Coralina (CC), Clarice Lispector (CL), Chiquinha Gonzaga (CG), Cecília Meireles (CM), Vinícius de Moraes (VM), Virginia Woolf (VW), Anita Malfatti (AM) e Tarsila do Amaral (TA).

\section{- A punção venosa sendo fonte de sofrimento para os pais e acompanhantes.}

Vivenciar a punção venosa e interagir com as reações de sofrimento da criança constitui-se em uma grande fonte de sofrimento para os pais e acompanhantes, que dizem ficar abalados em razão do nervosismo da criança, não gostarem de ver seu sofrimento e presenciar a picada. Eles referem que ficam bastante nervosos durante e após a punção e arrasados com a situação. Eles também sofrem e ficam desagradados, quando o procedimento é realizado sem nada ser conversado com a criança e, ainda, por precisarem restringir o braço da mesma no momento da punção.

É, eu estou tremendo até agora. Eu não gosto de ver assim, nem dando injeção nem tirando sangue. Eu fico um arraso por dentro. (CC)

[...] então ela ficava nervosa, ela chega tremia. Então aquilo me deixava meio abalada. (CL)

Eu ficava chateada, porque eles não conversavam nem nada. Falavam para eu segurar o braço dela e pronto. (CG)

Embora desencadeie sofrimento, tanto a eles como à criança, a punção venosa é reconhecida pelos familiares como necessária para seu tratamento, determinando com que eles acabem se conformando com o procedimento por não terem como impedir essa situação.

Ah! normal, tem que tirar, né!?. (CM) 
A gente fica triste porque, ficar picando a criança assim! Mas é importante, énecessário. Énecessário para o tratamento da criança. (VM)

\section{- Aprovando o preparo da criança com o BT}

Os pais e acompanhantes aprovam o preparo da criança com o BT uma vez que reconhecem seus benefícios tanto para ela como para eles próprios. Eles referem que a criança fica mais calma e tranquila durante e após a punção e que o fato de poder brincar faz com que, durante o preparo, ela até esqueça o procedimento propriamente dito e no momento da punção, mesmo chorando, continue distraída. Enfatizam que percebem o BT como um instrumento eficaz para minimizar o medo da criança antes e na hora de sua realização.

Eu acho que resolveu. É bom que a criança, fica mais calma, né? [...] eu achei muito legal, um incentivo para a criança não ter medo na hora de tirar sangue. (CM)

Ela brincou com os bonequinhos de todo mundo, brincou com o coleguinha que estava do lado, depois brincou com outro coleguinha. (CL)

É bom, porque assim tirou o medo da criança né? Deu pra distrair um pouquinho também. (VM)

Além de acalmar, tranquilizar, distrair e minimizar o medo, outro beneficio, observado pelos pais e acompanhantes, é promover a compreensão e aceitação do procedimento pela criança. Eles referem que, porque ela aprende a fazer a punção venosa, fica mais calma e segura, pois sabe o que vai se passar na sala de procedimentos, não tendo surpresas no momento da punção e que essa compreensão faz com que aceite melhor a sua realização.

É que aí já sabe que vai ter agulha, o que vai ter lá dentro, então já fica mais amansada; não chega de surpresa não [...]. Ela já fica naquele medo. Ah! Vou entrar na sala e vou enfrentar uma agulha. Desse jeito não, ela fica ali preparada. (AM).

Eu me sinto segura e ela de certa forma também se sente segura. (CL)

Pelo fato de os pais e acompanhantes perceberem os benefícios do BT para suas crianças, eles os reconhecem como benefícios para si próprios, pois ficam mais calmos ao notarem que as pessoas brincam com as crianças durante o preparo, proporcionando-lhes atenção e cuidado. Isso os deixa mais tranquilos, seguros e com confiança no profissional.
As meninas que estavam brincando com ele tiveram todo o cuidado. E isso tudo deixa a gente mais tranquila, porque eu confio no pessoal aqui. (VW)

Eu me senti segura! Tinha gente ali que estava mostrando segurança para mim e para ela (CC)

Pelo reconhecimento de seus benefícios, os pais e acompanhantes aprovam o preparo da criança com BT com veemência e reconhecem essa intervenção como necessária e importante, merecedora de uma nota máxima, além de recomendarem que seja mantida porque ajuda a criança.

Isso é bom porque prepara a criança... É bom, eu gostei, muito bom. (VM)

Ótima! Na minha opinião, eu acho que a preparação deveria ser feita lá na creche. [...]. Eu gostei, dou nota dez, se desse para dar onze eu dava. Nota $\operatorname{dez!}(C G)$

\section{- Surpreendendo-se com a proposta e os resultados do preparo}

0 preparo com o BT é percebido pelos pais como uma novidade, uma proposta de intervenção diferente, que gera muitos benefícios em relação ao comportamento das crianças, antes e após a punção venosa. A partir de experiências vividas em outros serviços de atenção à saúde, eles comparam as reações do filho com e sem esse preparo e dizem-se surpresos com os resultados obtidos. Eles se surpreendem com a proposta de brincar com o próprio material da punção, que consideram fazer a diferença no preparo da criança.

É novo, porque nem todos os lugares tem isso. São poucos os lugares que tem essa preocupação de distrair a criança, preparar a criança para entrar na sala. [...] Então, fiquei com ele 7 dias nesse hospital e se tiver esse trabalho por lá é muito pouco, porque eu não vi. Tem que ter preparação. Com preparação, é melhor! (VM)

Foi bom, eu gostei. Pelo menos todas as vezes que eles colheram sangue eles choraram, espernearam. Agora não, foi tranquilo. [...] Olha, eles nem choraram, nem choraram pela primeira vez. (CG)

O bom é que ela está fazendo no boneco, né? Ela manipular o material faz diferença. É bem melhor do que você pegar e ir pra sala direto. (AM) 
Os pais reconhecem, inclusive, haver redução do tempo da coleta de sangue, pelo fato de a criança tornar-se mais colaborativa por saber o que ocorrerá com ela.

[...] foi direto para a coleta (em outro local). Aí foi pior ainda, ela teve mais choro, correu a sala inteira. Agora aqui não, a pessoa segurou (o braço da criança) e pronto! Foi mais rápido do que a primeira vez! (CM)

Eles também comparam a reação da criança antes, na instituição pesquisada, quando era sempre preparada para a punção venosa, e depois de uma hospitalização, em que 0 preparo não foi realizado e tudo era feito com pressa. As comparações demonstram claramente que a criança ficou traumatizada sem o preparo, sendo verbalizado que há uma grande diferença entre 0 atendimento hospitalar vivenciado e 0 dessa instituição. Nessa diferença, o que mais se destaca é a pressa dos profissionais do outro local. Segundo os pais, essa pressa impede que seja realizado um trabalho com diferencial que no atendimento à criança é garantido por uma comunicação adequada a seu entendimento, como o proporcionado pelo BT.

Por que a diferença é assim, a enfermeira daqui vem brinca, prepara e tal; e no hospital não, eles têm pressa. Então eles chegam, tem que tirar o sangue pronto e acabou. Aí tem que tirar na marra. A minha filha não gosta de que seja assim, na marra. [...] Desde bebê ela nunca deu trabalho. Na hora de tirar o sangue ela era a primeira. Ela nem tava aí [...]. Ela pegou pneumonia e ficou internada, teve que ficar picando ela toda hora, toda hora. Aí ela pegou um pavor. (CL)

Embora os pais e acompanhantes aprovem o preparo com o BT e reconheçam seus benefícios, tanto para eles como para as crianças, eles acabam criando expectativas em relação ao comportamento dela durante a punção, que, quando não são alcançadas, geram surpresa e grande frustração, pois eles esperam que, com o preparo, as reações como o choro e as agressões da criança sejam minimizadas ou suprimidas, o que nem sempre se verifica.

Ele reagiu do mesmo jeito que ele sempre reage. Aí, sempre que vem tirar sangue é sempre isso, sempre ele grita berra, se puder bater ele bate e, se deixar, ele sai correndo de dentro da sala. [...] Ele brinca, ele faz tudo normal, mas na hora que chega dentro da sala, que ele vê que é com ele, ele começa a escandalizar. (TA)

Pelo fato de as crianças terem sido preparadas, os pais e acompanhantes nem sempre compreendem tal reação. Eles avaliam que, em diversos momentos, a criança chora demais e, embora até reconheçam que há situações nas quais o choro é justificável, julgam que não seria preciso chorar tanto, visto que tudo é conversado com ela.

Ah, eu não gosto de ver ele chorando não! Ele chora muito, chora sem motivo nem nada. (AM)

Por que vocês conversam tudo, mas não sei o que acontece com ele. (CM)

Como esse comportamento mais reativo da criança gera frustração, os pais e acompanhantes tentam compreender essas reações, buscando explicações que as justifiquem. Ter sido puncionado anteriormente diversas vezes é considerado pelos pais como um fator estressante e gerador de trauma à criança. Assim, relembram situações de tratamento envolvendo procedimentos intrusivos, sobretudo em hospitalizações, que consideram terem sido causadores de traumas e reconhecem que, quando a vivência foi muito traumática, as crianças não a superam mesmo brincando, dizendo que algumas não suportam nem olhar para a agulha.

Aí, depois que ela pegou pneumonia e ficou internada, teve que ficar picando ela toda hora, toda hora. Aí ela pegou um pavor! (CL)

[...] como ele ficava nervoso, o sangue prendia, não saía! Tinham que ficar furando ele. (TA)

\section{- Reconhecendo os avanços e o valor da equipe de enfermagem}

A abordagem da criança com o BT foi percebida como sendo um avanço da assistência de enfermagem, pois os pais e acompanhantes reconhecem que, dessa forma, as crianças estão sendo bem cuidadas e tratadas. Segundo eles, o preparo com o BT gera aproximação e estabelecimento de confiança, proporcionando uma relação muito bonita entre a equipe e a criança. Para os pais e acompanhantes, a intervenção com o BT é uma prova de que a enfermagem está evoluindo em direção ao paciente, demonstrando o amor que alguns enfermeiros tem à profissão.

Eu acho que dia a dia a enfermagem está evoluindo mais PARA o paciente, PARA! Porque tem muitos (profissionais) que estão com amor na profissão. (CG)

[...] é uma convivência que não dá pra parar. Ela adora a C (técnica de enfermagem), ela é apaixonada pela $C$, tá com ela todo o tempo ali 
na creche, mas onde ela vê a P!!! (Enfermeira da instituição) É uma convivência bem bonita!(CL)

[...]Por que a diferença é assim, a P vem brinca, prepara, e tal? E no hospital não, eles têm pressa. Então eles chegam, tem que tirar o sangue pronto e acabou. Aítem que tirar na marra. A.M.(criança) não gosta de que seja assim, na marra. (CL)

\section{DISCUSSÕES}

Os dados revelados pelo estudo reiteram o quanto 0 procedimento intrusivo é uma fonte de sofrimento para os pais e acompanhantes, não só pelo fato de presenciarem as reações de sofrimento do filho, como também por não poderem impedir esse sofrimento, visto que a dor é inerente à punção e porque eles reconhecem sua necessidade no tratamento da criança. Desse modo, acabam se conformando com a realização do procedimento.

Embora este estudo tenha sido realizado em situação de atendimento ambulatorial, os achados são similares aos de outros trabalhos que evidenciam o sofrimento dos pais decorrente desse procedimento em experiências de hospitalização de seus filhos. De acordo com um estudo, a dor da mãe ocorre pelo fato de se sentir impotente e incapaz de livrar o filho do sofrimento, de modo que a tarefa de acompanhar a criança para ser submetida a inúmeras picadas, por ocasião da punção venosa, torna-se um fardo muito penoso. ${ }^{3}$

Outro estudo ressalta que a mãe reconhece 0 sofrimento do filho no momento da punção venosa e percebe a dor da criança como sua própria dor, transpondo para a situação vivida seu medo e sua percepção de dor. Assim, perante a necessidade da punção venosa, o sofrimento emocional das mães confunde-se com o sofrimento físico, fazendo com que elas se sintam mal, ${ }^{5}$ o que também foi relatado pelos pais deste estudo.

A análise das entrevistas revelou, também, que os pais aprovam o BT como intervenção de preparo da criança para a punção venosa e consideram seus resultados satisfatórios e benéficos à criança, pois, segundo eles, esse preparo a acalma, tranquiliza e distrai; diminui seu medo; favorece a compreensão e aceitação do procedimento e promove a segurança.

Na prática assistencial à criança, os benefícios do BT têm sido apontados em outros estudos. Em um deles, que investigou como os pais percebiam a utilização do BT em crianças hospitalizadas, com doenças crônicas e na situação de retirada de pontos de sutura, os pais referiram os mesmos benefícios. ${ }^{13}$ Outro estudo, que entrevistou enfermeiros que utilizam o BT no cuidado da criança, revelou que esses profissionais percebem como benefícios desta prática o fato de permitir prepará-la para os procedimentos, promover o bem- estar da mesma, minimizar o medo, acalmá-la e favorecer seu desenvolvimento e socialização. ${ }^{14}$

Uma pesquisa recentemente publicada ampliou a evidência desses benefícios, no sentido de o BT ter se mostrado efetivo como estratégia de alivio da dor e da tensão da criança durante a realização do curativo cirúrgico, uma vez que $97,03 \%$ das crianças tiveram redução do escore de dor após a intervenção com o BT. ${ }^{15}$

Em nossa experiência profissional, o fato de poder brincar enquanto aguarda a punção venosa desvia o foco de atenção da criança do procedimento propriamente dito, diminuindo a tensão da espera, ao mesmo tempo em que ela aprende sobre o mesmo e pode descarregar essa tensão.

Como consequência de vivenciarem os benefícios do BT para os filhos, os pais reconhecem seus benefícios para eles próprios. Observar maior tranquilidade da criança e atribuir significado de atenção, carinho e reconhecimento aos profissionais fazem com que eles se sintam mais calmos, tranquilos e seguros, o que também está descrito nos estudos anteriormente referenciados, tanto pelos pais como pelos enfermeiros que foram, respectivamente, seus sujeitos. ${ }^{13-14}$

A literatura enfoca, ainda, que o brincar aparece como sinal de saúde na perspectiva das mães, e, dessa forma, ver os filhos brincando no contexto de assistência à saúde, permite que elas se sintam menos angustiadas e ansiosas podendo, inclusive, relacionar-se de maneira mais confiante com as crianças. ${ }^{16}$

No entanto, durante a punção, algumas crianças continuam a apresentar reações de choro e gritos, como formas de exteriorizar seus sentimentos, fazendo com que os pais se decepcionem, frustrando-se. Esta frustração se dá pelo fato de não compreenderem o motivo de os filhos apresentarem tais reações, mantendo o mesmo comportamento das punções anteriores, mesmo após terem sido preparadas com o BT. 0 achado nos leva a refletir sobre a importância de os pais serem orientados quanto aos objetivos da criança ser preparada para um procedimento e que este preparo não é determinante de mudança de comportamento como as reações de choro, até porque não assegura a redução da dor física decorrente da punção.

0 preparo para procedimentos tem como objetivos: estabelecer relação de confiança com a criança; auxiliá-la, e a seus pais, a perceberem que são considerados pelo profissional; ajudá-la a se sentir segura para enfrentar a situação; proporcionar recursos que favoreçam a comunicação em relação à experiência; diminuir o medo e ajudar a liberar a tensão; substituir conceitos errados e fantasias, levando-a a entrar em contato com a realidade; apoiá-la para que expresse, de forma segura e apropriada, em seu nível de desenvolvimento, as emoções decorrentes da situação e fornecer meios para que a experiência seja o menos traumática possível e converta-se em uma possibilidade de crescimento à criança e seus pais. Assim, durante o preparo, a criança deve, inclusive, ser 
informada de que poderá chorar e manifestar-se durante o procedimento. ${ }^{6}$

Na tentativa de compreender os motivos dessa reação das crianças, os familiares relembram situações traumáticas de punções venosas, vivenciadas anteriormente em decorrência de doença e hospitalização, durante a qual a criança foi submetida a inúmeras e repetidas punções sem ter sido preparada apropriadamente.

Sabe-se que o fato de algumas crianças reagirem violentamente durante uma injeção pode decorrer de perceberem tal procedimento como uma punição por terem feito algo errado, uma vez que é comum serem ameaçadas pelos adultos que, se não comerem ou não se comportarem bem, o castigo será uma injeção, associando o castigo à figura do médico ou da enfermeira. ${ }^{2}$ Além disso, os pré-escolares costumam interpretar o procedimento como punição, por ser este o período crítico do desenvolvimento da consciência e do senso de iniciativa. ${ }^{6}$

Assim, reafirmamos que, embora o preparo da criança com o brinquedo ofereça condições para que ela expresse suas emoções de forma simbólica, favorecendo a catarse, ela poderá não mudar imediatamente seu comportamento, o que deve ser compreendido pelos profissionais de saúde e explicado aos pais.

Por experimentarem os benefícios, tanto para eles como ao seu filho, os pais reconhecem a importância dessa prática, aprovando o preparo da criança com o BT, mesmo quando ela demonstra medo e reage chorando no momento da punção. Os pais desta pesquisa que vivenciaram a utilização dessa prática pela primeira vez, inclusive, surpreenderam-se e reconheceram a diferença da reação dos filhos, após serem preparados.

Estudo realizado em um Pronto-Socorro Infantil revela a mesma surpresa e aprovação dos pais em relação à utilização do BT no preparo do filho para a punção venosa em situação assistencial de emergência, assim como os benefícios dessa intervenção à criança. ${ }^{17}$

À medida que os pais reconhecem os benefícios para o filho e para eles próprios e comparam esse modelo assistencial a outros vivenciados, passam a reconhecer a qualidade e a diferença do atendimento prestado pela equipe de enfermagem que utiliza o BT, por considerarem que eles e seus filhos estão sendo respeitados e valorizados como pessoas. Para eles, essa forma de assistir demonstra um avanço, uma evolução da Enfermagem e que está sendo praticada por pessoas que exercem a profissão com amor e competência.

0 reconhecimento e a valorização da equipe de enfermagem têm concordância com outros achados da literatura, segundo os quais o BT foi valorizado como importante intervenção de enfermagem, tanto pelos pais como pelos demais profissionais da área da saúde envolvidos na assistência à criança, ${ }^{14}$ de modo que fica colocado em evidência o próprio desenvolvimento da profissão.
Além disso, a questão relacionada ao manuseio do corpo da criança durante um procedimento, sem respeito à sua privacidade, chega a constituir-se num problema ético, ainda mais considerando que esse respeito é um dever prima facie do profissional que atua na área da saúde, ou seja, um dever que não pode deixar de ser cumprido, nem ser substituído por qualquer outro de mesmo nível de exigência. ${ }^{18}$ Assim, ter pressa não pode justificar a realização de um procedimento sem a criança estar adequadamente preparada.

Reforçamos, ainda, que além de favorecer a valorização da enfermagem, a utilização do BT atende ao preconizado pelo ECA, Capítulo II, do Direito à Liberdade, ao Respeito e à Dignidade, que determina em seu Artigo 15: "A criança e o adolescente tem direito à liberdade, ao respeito e à dignidade como pessoas humanas em processo de desenvolvimento e como sujeitos de direitos civis, humanos e sociais garantidos na Constituição e nas leis ${ }^{\prime \prime}$, pois permite que situações, mesmo desagradáveis, finalizem-se como promotoras de desenvolvimento, construtoras de conhecimento e aprendizagem, já que a criança, por meio da brincadeira, compreende o significado e os motivos pelo qual passará por um procedimento, no caso a punção venosa.

\section{CONSIDERAÇÕES FINAIS}

Os resultados do presente estudo ressaltam a importância de o BT integrar o planejamento da assistência à criança e à família, em função dos benefícios decorrentes de sua utilização, conforme ficou evidenciado nos resultados que foram por ele revelados.

A despeito de o preparo com o brinquedo ter sido realizado na situação de atendimento ambulatorial, para o qual a criança comparece ao serviço de saúde especificamente para a punção venosa, de modo que os familiares não se encontram com muito tempo disponível, pois precisam retornar com alguma urgência às suas atividades profissionais ou domésticas, é possível a criança ser preparada para este ou qualquer outro procedimento intrusivo.

Tal fato foi reconhecido pelos familiares participantes da pesquisa, de acordo com os quais, com o preparo, o tempo gasto para a punção venosa é inclusive menor. Isto se dá porque não há necessidade de restringir a criança e, em geral, por ela ser mais colaborativa e, consequentemente, por haver maior facilidade de se realizar a punção, com êxito, já na primeira tentativa.

Assim, reiteramos que o BT seja sistematicamente utilizado como intervenção de enfermagem no preparo da criança para procedimentos, independente do cenário onde a população esteja sendo atendida, e recomendamos que outros estudos relacionados a essa prática assistencial sejam desenvolvidos em ambulatórios e unidades básicas de saúde, tanto no que diz respeito ao preparo da criança e 
família para outros procedimentos como quanto à utilização do BT nas suas outras modalidades, o que não foi abordado nesse estudo.

\section{REFERÊNCIAS}

1. Ribeiro CA, Angelo M. 0 significado da hospitalização da criança préescolar: modelo teórico. Rev Esc Enferm USP. 2005; 39(4):391-400.

2. Angelo M. Hospitalização: uma experiência ameaçadora. In: Stern MHF. Quando a criança não tem vez: violência e desamor. São Paulo: Pioneira; 1986. p.101-08.

3. Oliveira I, Angelo M. Vivenciando com o filho uma passagem difícil e reveladora: a experiência da mãe acompanhante. Rev Esc Enf USP. 2000 jun; 34: 202-08.

4. Oliveira DE. Punção venosa da criança: uma vivência de sofrimento para a família [monografia]. São Paulo (SP): Escola Paulista de Medicina, Universidade Federal de São Paulo; 2003.

5. Pinto JP, Fernandes RAQ, Teixeira MB. A mãe e a punção venosa do filho hospitalizado: uma visão fenomenológica. Rev Paul Enferm. $2001 ; 20(2): 12-9$.

6. Ribeiro CA, Borba RIH, Rezende MA. 0 brinquedo na assistência à saúde da criança. In: Fujimori E, Ohara CVS. Enfermagem e a saúde da criança na atenção básica. Barueri: Manole; 2009. p.287-327.

7. Martins MR, Ribeiro CA; Borba RIH; Silva CV. Protocolo de preparo da criança pré-escolar para a punção venosa, com a utilização do brinquedo terapêutico. Rev Latino-am Enfermagem. 2001; 9 (2):76-85.

8. Ribeiro PJ, Sabatés AL, Ribeiro CA. Utilização do brinquedo terapêutico, como um instrumento de intervenção de enfermagem, no preparo de crianças submetidas à coleta de sangue. Rev Esc Enferm USP. 2001; 35(4): 420-28.

9. Lei $n^{0}$ 8.069, de 13 de julho de 1990. Dispõe sobre o Estatuto da Criança e do Adolescente e dá outras providências. [texto na Internet]. [citado 2008 out]. Disponível em: http://www.planalto.gov.br/ccivil 03/ LEIS/L8069.htm

10. Leite TMC, Shimo AKK. 0 brinquedo no hospital: uma análise da produção acadêmica dos enfermeiros brasileiros. Esc Anna Nery. 2007; 11(2): 343-50

11. Minayo MCS. 0 desafio do conhecimento: pesquisa qualitativa em saúde. $11^{\text {a }}$ ed. São Paulo: Hucitec; 2008.

12. Mayan MJ. An introduction to qualitative methods: a training for students and professionals. Edmonton, Canadá: International Institute for Qualitative Methodogy, University of Alberta; 2001.
13. Ribeiro CA, Borba RIH, Maia EBS, Carneiro F. 0 brinquedo terapêutico na assistência à criança: 0 significado da experiência para os pais. Rev $\mathrm{Soc}$ Bras Enferm Pediatr. 2006; 6:15-23.

14. Maia EBS, Ribeiro CA, Borba RIH. Brinquedo terapêutico: benefícios vivenciados por enfermeiras na prática assistencial à criança e à família. Rev Gaucha Enferm. 2008; 29(1):39-46.

15. Kiche MT, Almeida FA. Brinquedo terapêutico: estratégia de alivio da dor e tensão durante o curativo cirúrgico em crianças. Acta Paul Enferm. 2009; 22(2): 125-30.

16. Junqueira MFPS. A mãe, seu filho hospitalizado e o brincar: um relato de experiência. Estud Psicol. 2003; 8(1):193-97.

17. Medeiros G, Matsumoto S, Ribeiro CA, Borba RIH. Brinquedo terapêutico no preparo da criança para punção venosa em pronto socorro. Acta Paul Enferm. 2009; 22(n esp): 909-15.

18. Goldim JR. A ética e a criança hospitalizada. In: Ceccim RB, Carvalho PRA. Criança hospitalizada: atenção integral como escuta à vida. Porto Alegre: UFRS; 1997. p. 22-6.

\section{NOTAS}

a Trabalho vinculado ao Grupo de Estudos do Brinquedo - GEBrinq

\section{AGRADECIMENTOS}

Ao CNPQ pela concessão da bolsa de iniciação científica do Programa PIBIC e ao Centro Assistencial Cruz de Malta, pelo acolhimento para realização do presente estudo. 